\title{
TRUMP E A CRISE DA SOCIEDADE NORTE-AMERICANA: AS ELEIÇÕES DE 2018 - SIGNIFICADOS E PERSPECTIVAS
}

\author{
Rafael R. Ioris ${ }^{1}$
}

\begin{abstract}
Os Estados Unidos enfrentam hoje uma profunda crise política e social. O país se encontra polarizado como há muito tempo não ocorria, situação que foi confirmada nas últimas eleições legislativas em 2018 e que pautará o vindouro pleito presidencial no ano de 2020. Analisando de maneira detalhada os resultados das eleições do ano passado, este artigo busca tecer apontamentos interpretativos ligados às suas motivações e consequências de médio prazo. Da mesma forma, busca-se apontar algumas das principais implicações mais amplas decorrentes desses eventos, assim como as perspectivas de médio prazo para o país e a região.
\end{abstract}

Palavras-chave: Estados Unidos; comportamento eleitoral; polarização política; crise.

\section{TRUMP AND THE CRISIS OF THE AMERICAN SOCIETY:THE ELECTION OF 2018 - ITS MEANINGS AND PERSPECTIVES}

The United States faces today a historical political and social crisis, a process that was sharply reflected in the mid-term elections of 2018. This trend shall define much of the electoral behavior of 2020. Based on a close analysis events, the present piece offers some interpretive notes of the main causes and direct impact of last year's election for the country and the region as whole.

Keywords: United States; electoral behavior; political polarization; crisis.

\section{TRUMP Y LA CRISIS DE LA SOCIEDAD ESTADOUNIDENSE: LA ELECCIÓN DE 2018 - SUS SIGNIFICADOS Y PERSPECTIVAS}

Los Estados Unidos enfrentan hoy una crisis política y social histórica, un proceso que se reflejó claramente en las elecciones para el congreso en 2018. Esta tendencia definirá gran parte del comportamiento electoral de 2020. Basado en un análisis detallado de los acontecimientos, el seguiente artículo ofrece algunas notas interpretativas de las principales causas y el impacto de las elecciones de 2018 para el país y para la region en general.

Palabras clave: Estados Unidos; comportamiento electoral; polarizacion política; crisis.

JEL: D7; D70; D72.

\section{INTRODUÇÃO}

Os Estados Unidos estão imersos em um inverno intenso e paralisador. Quando da escrita deste artigo, em fevereiro de 2019, na fria cidade de Denver, tudo parece indicar que ainda teremos muitos dias frios e sombrios. Não apenas no sentido climático, mas, talvez, e acima de tudo, em um sentido mais metafórico, conforme busco explicitar a seguir.

1. Professor de história latino-americana e política comparada da Universidade de Denver. E-mail: <rafael.ioris@du.edu>. 
O governo federal norte-americano continua sem uma aprovação orçamentária de longo prazo. Além disso, nada indica que o país esteja mais próximo de uma resolução satisfatória do impasse criado pelo projeto de construção de um muro na fronteira com o México, proposta que foi carro-chefe da campanha de Trump em 2016. No seu pronunciamento anual junto ao Congresso (State of the Union), no início do mês, o presidente reiterou essa exigência como condição sine quo non para qualquer negociação orçamentária. Da mesma forma, confirmou sua retórica nacionalista e xenofóbica orientada a manter sua base entre os segmentos sociais de etnia branca e de menor poder aquisitivo e de educação formal, chave para sua eleição em 2016.

Contextualizado ao longo dessas linhas analíticas, e com a licença poética que espero que me seja permitida, o clima político norte-americano poderia, em grande medida, ser definido pela ideia de que o inverno já chegou e tende a permanecer aqui por algum tempo. Portanto, é no sentido de tentar esboçar uma reflexão prospectiva que inseri o fenômeno Trump, assim como as eleiçóes de meio de mandato de 2018, no contexto da crise que possibilitou a sua candidatura, e posteriormente a sua presidência.

Entendo que essa crise não começou, nem tampouco se esgota, com ele. Nesse sentido, este texto é divido em cinco seçóes, sendo a primeira esta introdução. $\mathrm{Na}$ segunda, busco situar a ascensão política de Trump dentro de um contexto histórico mais amplo, definido por dois processos de clivagem. Um, de natureza econômica, seria definido pela crescente deterioração dos salários dos segmentos médios e dos trabalhadores da populaçáo, levando a um patamar de concentração de renda que evoca os patamares de desigualdade do final do século XIX. A segunda clivagem, de natureza cultural e simbólica, reflete-se no distanciamento crescente entre as posiçóes políticas e visóes de mundo expressas por segmentos sociais residentes nas grandes cidades, especialmente nas regiōes costeiras do país, e os habitantes do interior dos estados centrais, de maneira especial, mas do país como um todo.

Nas seçóes 3 e 4, analiso em detalhes os resultados mais significativos das eleiçôes de 2018, com vistas a tentar tecer apontamentos interpretativos ligados às suas motivações e consequências de médio prazo. Por conseguinte, na conclusão do artigo, tento apontar o que vejo como implicaçôes mais amplas e perspectivas de médio prazo para o país e a região, com base em uma leitura das tendências atuais mais importantes.

Cabe ressaltar, por fim, que o artigo como um todo, pela própria natureza e pelos objetivos embasadores da sua elaboração, se baseia, mais do que tudo, em eventos que ainda estáo sendo analisados de maneira mais detalhada - o que justificaria o fato de seus dados e suas fontes serem sobretudo de natureza jornalística. Da mesma forma, os apontamentos aqui apresentados são de 
natureza prospectiva e, portanto, essencialmente provisórios, feitos mais com fins de inspirar maiores debates, reflexóes e estudos, do que prever acontecimentos ainda em gestação - tarefa sempre arriscada e de limitada aplicabilidade.

\section{TRUMP DENTRO DO CONTEXTO HISTÓRICO RECENTE}

Apesar da retórica talvez excessiva alinhavada neste texto, parece-me, de fato, que os Estados Unidos vivem nos dias de hoje uma realidade definida, em grande parte, por uma profunda crise, náo só econômica mas, acima de tudo, política, cultural e, mesmo, civilizatória ou existencial, que vem sendo construída ao longo dos últimos quarenta anos. Efetivamente, foi no final da década de 1970, em especial no início dos anos 1980 - período caracterizado principalmente pela retórica internacional belicista e políticas econômicas e sociais neoliberais do governo Reagan -, que se pode perceber um novo marco da história recente do país.

Lembremos que, para muitos, particularmente entre os grupos sociais de etnia branca das pequenas cidades do país, as mudanças culturais e políticas dos anos 1960 tinham ido longe demais. Isso, na visão desses grupos, seria demonstrado tanto na turbulência social dos movimentos sociais que se valiam de estratégias de confronto (por exemplo, Black Panthers Party), quanto pelo movimento pacifista e contra a Guerra do Vietnã. Aliado a esses fenômenos turbulentos de matriz mais política, cultural e social, a transformadora década de 1970, marcada profundamente também pela crise institucional e simbólica criada pelo escândalo do Watergate, presenciaria uma das maiores crises econômicas do pós-guerra no país, dando início a um forte processo de desindustrializaçẫo e queda do poder aquisitivo das camadas médias da população, com efeitos sentidos até os dias de hoje.

Dentro desse contexto de fadiga ampla e busca por alternativas, a retórica altissonante de Reagan foi vista por muitos como o caminho a ser seguido, náo obstante o claro teor conservador das políticas apoiadas pela nova coalizão no poder. Efetivamente, apesar de, na prática, ressuscitar a velha lógica econômica anterior ao New Deal, que levara o país à falência no início dos anos 1930, Reagan representava o "novo", o não político que seria capaz de apresentar um novo rumo a um país cada vez menos capaz de ser definido pela retórica da América branca e protestante, onde todos teriam as mesmas oportunidades de conquistar o famoso "sonho americano". Nesse sentido, o apelo de Reagan decorria, em grande parte, do fato de representar a promessa de realização de algo impossível, qual seja, reverter a passagem do tempo e levar de volta o país à década dourada dos anos 1950, quando o entáo ator de papéis secundários em Hollywood fazia algum sucesso ao lado de estrelas efetivamente de peso. 
Em linhas gerais, embora tenha havido crescimento econômico ao longo dos anos 1980, a chamada reaganomics resultaria em um profundo processo de financeirização da economia, desindustrialização da base produtiva e forte concentração de renda - dinâmicas essas que teriam sequência e efeitos ao longo dos trinta anos seguintes. De fato, durante os gloriosos anos 1990, quando os Estados Unidos se apresentavam ao mundo como ganhadores incontestáveis da Guerra Fria e Bill Clinton propagava as benesses da globalização aos quatro cantos da Terra, a economia norte-americana se convertia de vez em uma economia de serviços, e as empresas dos Estados Unidos passavam cada vez mais a transferir suas plantas industriais para países do mundo em desenvolvimento. O período foi definido, assim, pelo aprofundamento da flexibilização financeira iniciada na década anterior, bem como pela internacionalizaçáo das cadeias produtivas, chave da economia do país. Essa maior abertura comercial, a integraçáo econômica e a desregulamentaçáo dos serviços, especialmente nas finanças, levaria o país à retomada de níveis significativos de crescimento econômico, ainda que grande parte disso fosse oriunda dos mercados financeiros e não de ganhos de renda real para a grande maioria das famílias norte-americanas.

Embora a euforia da década dos 1990 tenha sido definida também por uma abertura maior no âmbito cultural da sociedade norte-americana - quando inúmeros estrangeiros bem qualificados passaram a viver e trabalhar em maiores números em várias partes do país, como no Vale do Silício, por exemplo -, a concentração de renda e a desigualdade crescente entre setores sociais e regióes geográficas com maior ou menor proximidade aos novos setores econômicos em expansão (por exemplo, a nova economia de serviços on-line) se aprofundavam de forma brutal, levando a um crescente ressentimento nacionalista, por vezes xenofóbico, que ajudaria a recolocar os conservadores na Casa Branca, com a vitória de George W. Bush na controvertida eleição do ano 2000.

Ainda mais belicistas, intervencionistas e nativistas que nos anos 1980, os já envelhecidos e cada vez mais ativistas neoconservadores (NeoCons) do início do século buscavam reavivar a lógica confrontacionista da Guerra Fria, ironicamente, dentro de um contexto de ausência clara de inimigos externos. Que o atentado de 11 de setembro de 2001 tenha, pois, sido rapidamente aproveitado pelos novos ocupantes do poder como justificativa para uma verdadeira cruzada internacional contra o chamado terrorismo de base religiosa islâmica não deveria apresentar nenhuma surpresa. Também não surpreendeu que o governo George W. Bush tenha se aproveitado do que era visto por muitos setores da chamada Middle America como comportamentos aberrantes, chocantes, inapropriados - os excessos cosmopolitas dos yuppies apoiadores de Clinton e dos agentes da chamada Nova Economia dos grandes centros urbanos do país - para reavivar uma narrativa tipicamente conservadora, por vezes populista de direita, que afirmava que a 
chamada verdadeira América estaria sendo desfigurada por influências estrangeiras, não importando que os ditos estrangeiros já fizessem parte há muito tempo da sociedade norte-americana.

Que esses sentimentos e discursos tenham sido muito estrategicamente nutridos e mesmo exacerbados durante o governo Obama tampouco deveria surpreender ninguém. Tratava-se, de fato, de um governo bastante moderado e que, em muitos aspectos, representava a continuidade das políticas econômicas liberalizantes dos anos 1990. O simbolismo do primeiro negro a ocupar a cadeira presidencial, contudo, não permitia que os fatos se apresentassem por seus próprios méritos. Assim, a narrativa de um país em crise, de uma nação que perdeu sua essência, onde grande parte dos seus habitantes não mais se reconhecia no país dos seus pais e que queria, portanto, ter o "seu país" de volta, deixa de ser um discurso marginal de extremados não representativos da maioria da população e passa a se colocar como real opçáo política no centro (mainstream) da narrativa e dos debates políticos.

Cabe ressaltar, porém, que, para ser possível, esse processo precisava de um canal próprio de expressão que o legitimasse dentro do processo político formal. O outsider contumaz, o não político perfeito, o empresário agressivo e celebridade midiática recorrente, Donald J. Trump, seria o veículo encontrado para permitir que essa dinâmica tão estranha pudesse se viabilizar. Criava-se, assim, uma lógica própria de utilização recíproca sem pudores ou princípios, em que quanto mais virulenta, xenofóbica, antidemocrática e confrontacionista fosse a retórica, mais azeitada seria a parceria entre Trump e sua base conservadora extremista, definida por um ultranacionalismo reacionário e apelos permanentes a uma suposta maioria branca ameaçada por todos os lados.

É, pois, dentro da inusitada confluência de forças políticas que traz Trump ao poder, e no substrato das transformaçóes econômicas, sociais, políticas e culturais dos últimos trinta ou quarenta anos, que entendo que os Estados Unidos se encontrem hoje. Ou seja, de certa forma, o país está novamente frente a um momento dilemático de possíveis definiçôes e redefiniçóes capazes de reorganizar de modo profundo os rumos da nação no contexto das próximas décadas.

Caberia ressaltar que, em condiçóes normais do funcionamento partidário e da base eleitoral, especialmente entre as camadas mais pobres e brancas, sobretudo dos estados do Meio-Oeste e Sul do país, talvez um candidato tão extremo como Trump náo tivesse conseguido eliminar todos os concorrentes dentro das primárias eleitorais do Partido Republicano. E, se exitoso na disputa interna, teria tido maiores dificuldades para ganhar a presidência nas eleiçôes gerais. É certo que, de maneira não democrática, o colégio eleitoral o beneficiou.

Ainda assim, não houvesse uma crise sistêmica da representação política da democracia liberal (fenômeno que não se restringe ao caso dos Estados Unidos, mas 
se expande ao redor do mundo), assim como uma crise econômica continuada no país, refletida mais que tudo no empobrecimento absoluto e especialmente relativo dos setores médios e de trabalhadores assalariados, talvez uma retórica tão extremada como a de Trump tivesse mais dificuldades para se viabilizar. De maneira alternativa, porém, cabe levantar a hipótese de que talvez Trump somente tenha ajudado a revelar uma lógica subjacente à América profunda, lógica esta que, se durável, apresentará enormes dificuldades ao país, no curto e mesmo no médio prazo.

Qual das duas possibilidades estamos de fato vivenciando é algo que, entendo, não esteja ainda muito claro. Especulações a respeito, portanto, só podem ser feitas de maneira tentativa e provisória. O certo é que as instituiçóes políticas norte-americanas passam hoje por um teste muito forte, cujo resultado ainda está por ser mais bem definido. $\mathrm{O}$ que este texto tenta alinhavar no que segue são possíveis cenários, com base nos últimos desdobramentos eleitorais congressuais de meio de mandato (mid-term elections) e nos últimos desdobramentos de importantes processos políticos e legais em curso na grande potência norte-americana.

\section{AS ELEIÇÕES DE MEIO DE MANDATO DE 2018 NOS ESTADOS UNIDOS: SÍNTESE E ANÁLISE DOS PRINCIPAIS RESULTADOS}

Olhando retrospectivamente, poderíamos afirmar que os dois primeiros anos do governo Trump foram marcados por um forte desprezo e confrontação constante com órgãos da mídia e da oposição no Partido Democrata. O processo de polarizaçáo política e cultural nos Estados Unidos foi iniciado muito antes da ascensão ao poder de Trump, como já apontado. Com figura de retórica tão agressiva e polarizadora na presidência, as divisôes políticas e também socioculturais adquiriram, porém, novas dinâmicas e matizes.

Mantendo a retórica e o estilo da campanha presidencial de 2016 desde o início do mandato, o novo presidente republicano se disse sob ataque da imprensa de notícias falsas (fake news), tentando assim se resguardar de maneira preventiva dos naturais escândalos que sua administração viria a se envolver - os quais, quase que de forma profética, não demorariam muito a aparecer. De fato, já nos primeiros meses de governo, uma série de revelaçóes sobre o envolvimento do governo russo na eleição vieram à tona, levando Trump a pressionar o então chefe do Federal Bureau of Investigation (FBI), James Comey, a não investigá-lo pessoalmente, o que foi recusado e provocou sua demissão logo em seguida. Esses eventos ganhariam uma enorme dimensão, forçando o Departamento de Justiça (DOJ), mesmo que a contragosto, a criar uma força-tarefa para investigar o assunto. ${ }^{2}$

2. Mais detalhes sobre a controversa demissão de James Comey e a consequente criação da força tarefa do promotor independente disponiveis em: <https://www.cnn.com/specials/politics/james-comey-firing > e <https://www.justice.gov/ opa/press-release/file/967231/download>. 
Com base nesses eventos, e consequentes ventos políticos contrários, ao longo do veráo norte-americano de 2018 , quando o foco do mundo político se dirigia para as eleiçóes de meio de mandato, havia um crescente otimismo entre os democratas em relação às eleiçóes congressuais e de vários estados. Isso derivava, em grande parte, de uma maior mobilização das bases eleitorais democratas, especialmente entre movimentos sociais, assim como no crescente desgaste do governo Trump, que, além das contínuas revelaçōes sobre a interferência russa nas eleiçôes, provavelmente com a participação de membros de sua campanha presidencial, também perdia membros de seu gabinete e principais agências reguladoras, por exemplo, a Agência de Proteção Ambiental (Environmental Protection Agency - EPA), por escândalos de corrupção ou inépcia.

Tudo parecia fazer crer que em novembro o país presenciaria a chamada "onda azul" (cor do Partido Democrata), não fosse o fato de que o processo de aprovaçáo do indicado de Trump à vaga deixada na Corte Suprema pelo ministro Kennedy, o ultraconservador juiz Brett Kavanaugh, viesse a se tornar uma "causa célebre" entre as bases republicanas, que entendiam que as denúncias de abuso sexual por parte do juiz, quando ainda jovem, representavam um complô democrata contra um juiz qualificado para o cargo. ${ }^{3}$

Ao longo dos meses de setembro e outubro do mesmo ano, o processo se polarizou fortemente. Os republicanos viam as acusaçôes como um ataque frontal contra um juiz que viria a consolidar uma maioria conservadora na Corte, enquanto os democratas tomavam o processo como uma oportunidade única para fortalecer o combate ao abuso sexual contra mulheres no país. As bases de ambos os partidos acabariam por se mobilizar de forma expressiva em torno desse tema nas eleições no mês seguinte. Assim, embora tenha confirmado importantes vitórias democratas, na Câmara e em vários estados, inclusive com a eleição de deputados de viés bastante progressista, como Alexandria Ocasio-Cortez, em certa medida o resultado das eleiçóes mostrou um país profundamente dividido, já que, no Senado, os republicanos não só mantiveram o controle da casa mas ampliaram em dois votos a sua maioria.

Ainda assim, os democratas conquistaram vitórias importantes, entre as quais a ampliação de sua base na Câmara em quarenta cadeiras, obtendo assim a maioria e a presidência da casa congressual. Mais importante, talvez, tenha sido o fato de que o partido da oposição ao presidente tenha atingido um recorde de votos no eleitorado em geral, obtendo 9 milhôes a mais do que os eleitores que votaram no Partido Republicano. Esses ganhos confirmaram a mobilização do eleitorado democrata em todo o país, já que, mesmo em distritos onde o partido não obteve a cadeira na Câmara, seus votos aumentaram. Apesar disso, dada a 
lógica do sistema distrital e do mecanismo do colégio eleitoral, tal maioria não se refletiu em vitórias mais expressivas ou em simples vitória. Foi o que se deu em 2016, quando Hillary Clinton foi derrotada em sua campanha pela presidência apesar de ter obtido cerca de 3 milhóes a mais de votos.

Outros ganhos importantes do Partido Democrata, embora por vezes mais de caráter simbólico do que demonstrativos de uma efetiva mudança ampla do eleitorado em geral, se deram na eleição de mulheres indígenas e muçulmanas para a Câmara Federal, de um governador assumidamente gay no estado do Colorado - onde o partido obteve controle total do Executivo e Legislativo estaduais -, o aumento no número de mulheres no Congresso em geral e a redução da idade média dos representantes federais do país. Os democratas assumiram o poder também em sete estados até então em mãos republicanas, com ganhos legislativos associados à estratégia, já que o desenho dos distritos eleitorais para a Câmara é feito pelas assembleias legislativas de cada estado com base no censo que, nesse caso, será feito em 2020. Houve também ganhos democratas em estados-chave, como Pensilvânia, Michigan e Wisconsin, o que demonstra a precariedade da vitória de Trump nesses lugares em 2016. Por fim, os democratas ainda conseguiram assumir em distritos sob controle de republicanos nos últimos trinta anos, como no sul da Califórnia. ${ }^{4}$

Por sua vez, verificou-se que não houve um repúdio claro a Trump e a seu partido. De fato, as enormes expectativas dos democratas por ganhos em estados importantes como Texas e Flórida não se confirmaram. No Texas, o candidato Beto O'Rourke tentou, sem sucesso, derrotar o senador republicano Ted Cruz, candidato a reeleiçáo. Na Flórida, os republicanos conseguiram, ainda que de maneira apertada, a maioria dos votos e, portanto, o controle do estado, assim como assumiram ambas as cadeiras do estado no Senado. ${ }^{5}$

Assim, ainda que tenha havido um aumento dos votos democratas em ambos os estados e a base do partido tenha se mobilizado de forma inédita, o que se confirmou é que o segundo e o terceiro maiores colégios eleitorais do país ainda devem permanecer sob controle republicano nos próximos anos. Na mesma direção, e como mencionado anteriormente, no Senado norte-americano, os republicanos mantiveram o controle da casa, até mesmo ampliando sua maioria.

Note-se ainda, como também apontado anteriormente, que, em função do desenho dos distritos eleitorais e especialmente dos sistemas de colégio eleitoral para

4. Mais detalhes sobre os resultados eleitorais estão disponíveis em: <https://www.politico.com/election-results/2018/ pennsylvania/; <https://www.politico.com/election-results/2018/wisconsin/>; <https://www.politico.com/election-results/2018/ michigan/>; e <https://www.nytimes.com/interactive/2018/11/06/us/elections/results-california-elections.html>.

5. Informações disponíveis em: <https://www.washingtonpost.com/election-results/texas/?utm_term=.7328492a5027>; e $<$ https://www.washingtonpost.com/election-results/florida/?noredirect=on>. 
a eleiçẫo presidencial, os votos para o Senado não se organizam segundo uma lógica estritamente democrática, ou seja, com o voto de cada eleitor tendo o mesmo peso no resultado final. Apesar de terem obtido cerca de $56 \%$ dos votos para o Senado, os democratas detêm hoje 49 cadeiras naquela Casa-incluindo dois senadores que votam junto com os democratas na maioria dos casos, mas que se declaram independentes. ${ }^{6}$

De maneira particularmente dolorosa para os democratas, as derrotas, ainda que apertadas, dos candidatos ao Senado no Texas e na Flórida devem requerer do partido uma reavaliaçáo de como seguir se mobilizando nesses estados. O chamado voto hispânico, sempre aventado como o fator que tornaria ambos os estados azuis, ou pelo menos roxo, insiste em não se materializar. Da mesma forma, parece muito difícil, tendo em vista os estados onde eleiçóes para o Senado estão previstas para 2020, que o cenário atual nessa casa congressual se altere, a menos que os prospectos de uma eleiçáo renovadora para a Câmara e Presidência nesse ano - ainda incertos apesar de maiores do que há três meses - venham a influenciar também esses pleitos que, em essência, são de natureza estadual. ${ }^{7}$ Assim, em seu conjunto, quais as principais conclusóes que poderiam ser tiradas desses acontecimentos?

Em primeiro lugar, entendo que, como antecipado, em vez da tal onda azul, o que as urnas demonstraram foi um quadro de polarização política que se consolida. Por um lado, apesar da mobilização surpreendente dos republicanos, em um contexto onde esse partido controlava tanto o Executivo como o Congresso, os ganhos democratas foram, sem dúvida, muito significativos e apontam para um cenário de crescente e, espera-se, contínua mobilização de suas bases.

Por outro lado, foi bastante surpreendente que os republicanos tenham conseguido ativar seus apoiadores de tal forma. Normalmente, nesse tipo de eleição, o partido da oposição é o que consegue atingir altos níveis de mobilização eleitoral. No dia 6 de novembro de 2018, tivemos, de fato, uma das maiores participaçóes eleitorais em eleiçóes de meio de mandato, com comparecimento de cerca de 49,2\% do eleitorado. Foi o segundo maior índice da história, nesse tipo de eleição, superado apenas em 1914, quando - com a eclosão da Primeira Grande Guerra - cerca de 50\% dos eleitores norte-americanos compareceram às urnas (Stewart, 2018).

$\mathrm{O}$ que parece certo é que se confirmou um quadro de divisão política bem demarcado no país, talvez mesmo seu aprofundamento. Essa polarização é refletida nos votos dos dois partidos hegemônicos, mas que em muito os transcende. Revelou-se, assim, uma vez mais, embora de maneira não de todo inovadora (já que tais parâmetros vêm sendo demonstrados ao longo dos últimos vinte anos), a existência de duas Américas claramente distintas: uma América litorânea e uma América dos estados do centro do país; uma América urbana e 
uma América rural; uma América das novas indústrias limpas e de serviços e uma América desindustrializada, enferrujada (Rust Belt), de atividades econômicas sujas e extrativistas, como o carvão; uma América laica e inclusiva e uma América religiosa e dogmática; e por fim, uma América branca e uma América mestiça.

É inegável que nada no mundo concreto é tão esquemático assim. É fato, inclusive, que muitos dos membros da dita América liberal também são brancos. Ainda assim, é também certo que a base de apoio mais forte dos republicanos - e especialmente de Trump - se encontra entre os norte-americanos brancos, nos estados centrais, menos urbanos e economicamente menos ligados às indústrias novas, de alta tecnologia e de energias renováveis. Nesse sentido, dentro de um quadro de divisão interna consolidada, coloca-se um cenário difícil e volátil para o país.

O país refletido nas urnas precisa ser entendido como um país em fluxo, cada vez mais diverso, multiétnico e multicultural. Ele é, contudo, uma nação cindida de maneira profunda, em conflito consigo mesmo, com enormes dificuldades, portanto, de se ver no espelho. As eleiçôes refletiram, sim, um país mais jovem, poliglota e multirreligioso. O pleito, entretanto, revelou também novas iteraçôes do profundo racismo histórico contra grupos não brancos, anglo-saxôes e protestantes, que permanece forte e profundamente arraigado em múltiplas partes do país.

Completando o quadro, ficou claro que o peso da indústria fóssil continua enorme, já que candidatos associados à agenda ambiental e proposiçóes estaduais de controle de emissóes, em geral, náo foram apoiados pelo eleitorado. E, embora se perceba uma crescente preocupação relativa à temática do mapeamento politicamente orientado dos distritos eleitorais, especialmente pelo Partido Republicano, esse recurso continua sendo utilizado de maneira ampla ao redor do país, com continuados efeitos deletérios ao processo democrático em geral.

$\mathrm{O}$ que se percebeu também foi um dos maiores problemas estruturais da democracia norte-americana, qual seja, o fato de o peso do voto de cada eleitor não ser de forma alguma equivalente ao voto de outro. Isso faz parte da lógica historicamente oligárquica que rege o desenho da Câmara Alta nos parlamentos ocidentais. Algo, no entanto, que vem sendo demonstrado de forma nítida em cada eleição nos últimos anos é a existência de um descompasso generalizado também no peso do voto dos eleitores para a Câmara de Deputados. Essa desigualdade decorre da sub-representaçáo dos estados mais populosos e do recorte dos distritos em cada estado, concebido em geral para garantir maiorias ao Partido Republicano. Dessa forma, os resultados eleitorais tendem a revelar uma representação congressual (assim como presidencial) não equivalente ao voto popular expresso nas urnas - algo que tanto as eleiçóes de 2016 como as de 2018 demonstraram, só para citar as mais recentes, conforme mencionado anteriormente. 
Dentro da citada polarização entre grandes centros urbanos e o voto disperso pelo interior dos estados e do país em geral, outro aspecto que chama atenção na eleição de 2018, quando comparada com a eleição de Trump, em 2016, é a significativa perda de apoio do Partido Republicano entre mulheres brancas, portadoras de educação superior e habitantes dos chamados subúrbios de classe média das grandes cidades - seja das costas litorâneas, ou mesmo nos estados centrais, como Colorado, Michigan, Wisconsin e Ohio -, tradicionalmente eleitoras do partido (Nort, 2018).Esse setor do eleitorado tem se demonstrado chave para qualquer eleição desde o início dos anos 1990, quando Clinton foi o primeiro a mobilizá-lo, em parte sob o rótulo de blue dog democrats, um eleitorado volátil que pode ou não votar com o partido, dependendo do contexto conjuntural de cada eleição.

Confirmou-se, pois, que a base cativa de Trump se concentra entre homens brancos, especialmente sem educação superior, assim como entre grupos religiosos conservadores, em geral também brancos e de base socioeconômica mais baixa. São exatamente esses eleitores que tendem a ser mais facilmente mobilizados com base em uma retórica nacionalista radical - por vezes com forte conotaçáo supremacista branca -, anti-intelectualista, isolacionista, protecionista e xenofóbica. Esses setores vêm sendo muito eficientemente articulados por Trump e seus apoiadores e ativados de maneira constante por meios de comunicação de massa de viés ultraconservador, especialmente TV e rádios AM ao redor do país.

Da mesma forma, aprofundou-se o radicalismo e dogmatismo das bases trumpistas, pois, no mais das vezes, os ganhos democratas na Câmara Federal ocorreram pela perda de votos de candidatos republicanos de viés moderado, ao passo que republicanos abertamente trumpistas tenderam a se eleger. De fato, mesmo que a comparação entre distritos onde republicanos e democratas se saíram bem seja afetada pelas diferenças de composição - demográfica, política, ideológica, religiosa -, o produto final foi um Congresso mais polarizado, com lados menos abertos à negociação e composição de posições políticas divergentes (Jones, 2018).

Como apontado anteriormente, é inegável que muito da manutenção do peso do voto conservador e sua expressão na eleição de candidatos conservadores (ou mesmo reacionários) no Partido Republicano têm dependido, já há décadas, do desenho injusto e desequilibrado dos distritos eleitorais, assim como da restrição dos votos das chamadas minorias, especialmente entre afro-americanos, latinos e pessoas de mais baixa renda.

Ainda que essas manobras façam parte de uma longa e trágica história de exclusão do voto de grupos não majoritários do eleitorado que sempre definiu a história dos Estados Unidos, desde os anos 1960, com a passagem das legislaçôes federais de defesa dos direitos civis e políticos de todos cidadãos, esses 
mecanismos de supressão eleitora vinham enfrentando dificuldades para serem utilizados. A trajetória de democratização efetivada do eleitorado, contudo, tem sido erodida nos últimos anos, especialmente na última década, com decisóes polêmicas da Suprema Corte norte-americana limitando a aplicabilidade dessas legislaçóes (Douglas, 2018). Como vem sendo demonstrado em vários estado nas últimas eleiçóes - especialmente na Carolina do Norte já há algum tempo e nas últimas eleições na Geórgia -, o Partido Republicano não tem tido nenhum tipo de escrúpulo em se valer de novas formas de exigências legais para impedir que eleitores, sobretudo negros e hispânicos, consigam votar em diversas partes do país (North Carolina..., 2018; Lopes, 2018).

Assim, apesar dos esforços continuados de movimentos sociais de base, religiosos e seculares - que vêm tentando trabalhar com esses grupos no sentido de obter os documentos exigidos pelas novas regras impostas pelos republicanos $^{8}$-, e de organização nacionais de direitos civis e políticos (por exemplo, a American Civil Liberties Union - ACLU), que combatem juridicamente essas restriçóes ao sufrágio universal no país, parece certo que ainda continuaremos assistindo por um tempo a um importante descompasso entre a expressão, possível ou efetiva, do voto popular e a representação política formal - no Congresso, nas assembleias e executivos estaduais, assim como na Presidência.

\section{AS ELEIÇÕES DE 2018: IMPLICAÇÕES DE CURTO E MÉDIO PRAZOS}

Um mês em política é uma eternidade! Embora excessivamente usada, essa máxima da política parece aplicável nas questóes aqui examinadas. Desde as eleições de novembro até a elaboração deste texto, lá se vão mais de três meses. Nesse meio-tempo, os Estados Unidos passaram por uma nova crise gerada pela falta de aprovação orçamentária, derivada da ausência de um acordo entre os democratas, agora com a maioria na Câmara, e Trump. Como resultado dessa discordância, o país ficou privado de serviços náo essenciais providos pelo governo federal durante o mais longo período de sua história.

Para além das questóes diretamente ligadas ao temperamento de Trump, que criou o primeiro fechamento do governo mais por birra do que por visão estratégica, convém apontar alguns elementos do que entendo serem as grandes variáveis a influenciar o contexto político norte-americano nos próximos dois anos.

O primeiro eixo de desdobramentos que deverá ter um papel-chave se refere às investigaçóes conduzidas pelo promotor independente Robert Mueller, ex-diretor do FBI e figura de peso reconhecida pelos dois principais partidos.

8. Por exemplo, duas formas de documento oficial com foto para poder votar e registro eleitoral a ser feito meses antes da eleição. 
A menos que o teor do relatório seja explosivo, o que não acredito que venha a acontecer, acho difícil que os republicanos venham a arregimentar forças contra Trump. De similar importância, a forma como os democratas irão se comportar na Câmara no próximo ano e os procedimentos de escolha de seus candidatos para enfrentar os republicanos (presumivelmente, com Trump) em 2020 são pontos que merecem um detalhamento maior.

Cabe ressaltar, a princípio, que não está claro, nem mesmo para o partido, como os democratas deveriam agir no Congresso. Irão eles valer-se de sua maioria para tentar dar início a um processo de impeachment? Serão uma oposição ferrenha a tudo que vier da Casa Branca, ainda que sem tentar remover o presidente do cargo? Ou irão tentar apresentar propostas próprias, dispondo-se a negociar com o Executivo, mesmo que ocupado por Trump?

A depender de como o partido venha a se comportar - se é que conseguirá ter uma linha unívoca de ação -, deve variar também o comportamento de Trump, e a imagem de ambos junto do eleitorado se projetará de maneiras diferentes. Vale lembrar aqui o arraigado pragmatismo e conservadorismo político, reiteradamente manifestos pelo eleitorado norte-americano, a fim de apreciar melhor as opçóes mencionadas.

Embora vários congressistas novatos do Partido Democrata tenham um perfil mais progressista, ainda é verdade que - talvez como reflexo mesmo do humor médio da população, como um todo - o partido continua tendo um perfil bastante moderado, agindo basicamente como uma agremiação de centro, com traços de centro-esquerda. Na mesma direção, os parlamentares do partido que acabaram de derrotar candidatos republicanos em distritos por estes controlados ao longo de muitos anos, como no sul da Califórnia, são, por sua vez, bastante moderados em seus perfis, algo que certamente teve a ver com suas vitórias.

Da mesma forma, apesar das perdas republicanas que permitiram a maioria democrata na Câmara, é fato que vários candidatos próximos a Trump também garantiram suas reeleições, o que demonstra não ser completamente certo que o eleitorado como um todo tenha visto as eleiçóes congressuais de 2018 como um referendo sobre o presidente. Isso requer cautela, por parte dos democratas, na definição de como prosseguir.

É certo que a atuação dos democratas no Congresso exercerá forte influência na projeção da imagem do partido frente ao eleitorado em geral. Ainda não está claro, contudo, se ele será visto como uma agremiação simplesmente oposicionista (partido do não) ou como um partido viável, detentor de uma agenda capaz de agregar apoio entre variados segmentos da população desse complexo e diverso país.

Em relação ao eventual nome do candidato do partido para enfrentar Trump em 2020, tampouco está certo como os democratas devem se comportar. Talvez com 
o nome de Trump na cédula eleitoral, no caso de uma campanha por sua reeleição em 2020, os recentes ganhos democratas em estados-chave como Pensilvânia, Michigan e Wisconsin - onde Trump ganhou em 2016 - venham a ser eliminados. Essa talvez seja mesmo a tendência mais provável, caso a economia norte-americana continue a crescer com baixos níveis de desemprego, como nos últimos dois anos.

No mesmo sentido, os ganhos parlamentares recentes dos democratas em estados já seguramente "azuis", como a Califórnia, onde Trump é muito antipatizado, não são úteis na eleição majoritária. Nesses estados, não importa se a vitória do partido se dê por $50 \%$ mais um voto ou por $90 \%$ dos votos. Certamente, também nos estados-chave da Flórida e do Texas, a história poderia ser totalmente diferente caso os democratas conseguissem uma maioria, ainda que mínima. Essas expectativas, contudo, ainda que sempre presentes no cenário otimista dos consultores democratas de plantáo, ainda não parecem ser realistas, pelo menos no curto prazo, conforme demonstrado na última eleição.

Também não parece claro, nem mesmo para os consultores de plantão, se os democratas deveriam tentar lançar um candidato mais tradicional, com apelo nos estados do Meio-Oeste, onde a última eleição foi decidida, ou se deveriam optar por uma rota mais inovadora, tanto do ponto de vista simbólico como de uma perspectiva geográfica - ao centrarem seus esforços em estados do chamado "cinturão do sol", como Texas e Flórida, onde talvez um candidato hispânico, como Beto O’Rourke, ou Julian Castro, pudesse motivar o eleitorado latino, que tem ajudado a decidir eleiçóes desde 2000. Em outras palavras, deveriam os democratas tentar ganhar de Trump competindo no campo do adversário - isto é, no Meio-Oeste, predominantemente branco -, ou em um novo campo de disputa, onde teriam maior capacidade de inovação, com nomes novos, mais jovens e de etnia náo branca, representativos das mudanças populacionais dos últimos anos?

Ressalte-se ainda que a capacidade de ampliar seus votos nos estados com mais eleitores de descendência latina é, por ora, simplesmente potencial. Conforme anteriormente apontado, esse é um possível resultado que exigirá muito trabalho de base, sem garantias de sucesso. Da mesma forma, complicando ainda mais a vida do partido, os democratas, por um lado, precisam manter uma contundente oposição a Trump, de modo a manter a mobilização de suas bases, e, por outro, necessitam fazer cálculos estratégicos a respeito de como angariar votos junto a um eleitorado mais arisco às suas propostas, especialmente em estados majoritariamente conservadores.

Esse dilema se intensifica bastante no que se refere ao crescente entusiasmo, entre segmentos importantes dos apoiadores, por candidatos mais à esquerda do partido, como Bernie Sanders, assim como candidatos menos tradicionais, especialmente uma mulher, como Elizabeth Warren, ou especialmente uma 
mulher negra/mestiça, como Kamala Harris. Vale observar também que, em contraste interessante, enquanto no Brasil as classes médias vêm se mostrando nos últimos anos como o verdadeiro bastião do conservadorismo político, nos Estados Unidos, a articulação das posiçôes mais retrógradas, sejam elas relativas a temáticas culturais ou mesmo econômicas, tem encontrado terreno mais fecundo entre os segmentos socioeconômicos mais baixos, especialmente entre os segmentos populacionais de matriz étnica branca europeia.

Essa realidade faz com que, considerando as continuadas limitaçóes institucionais para uma representação efetiva dos votos, mudanças no contexto político norte-americano tendem, dentro de uma perspectiva histórica, a seguir um passo mais incremental do que transformativo e especialmente revolucionário. Ainda assim, conforme apontado no início do texto, esses padrões de comportamento se aplicam mais a condiçóes normais de funcionamento do sistema e lógica política média dos Estados Unidos do que a momentos de crise, como o atualmente vivido no país.

De um ponto de vista puramente especulativo, pode ser que os democratas venham a assumir o risco de ter um candidato não tradicional em 2020 e que isso venha a dar certo para seus interesses. Essa abordagem poderia servir, contudo, para que Trump pudesse arregimentar seu eleitorado cativo - nem de longe a maioria da população do país - de modo suficientemente eficaz, a fim de manter a presidência em mãos republicanas.

Antes de concluir esta reflexão, caberia apontar - ainda que de maneira muito especulativa - alguns possíveis desdobramentos capazes de catalisar as dinâmicas de curto prazo a ponto de desenhar uma possível resolução do impasse criado pela profunda polarizaçấo consolidada no país nos dias de hoje, ou, inversamente, talvez aprofundar esse cenário, visto aqui como o de uma longa e profunda crise nacional.

Caso Trump venha a radicalizar ainda mais sua retórica - partindo do princípio de que isso seja possível -, como resposta a uma realidade onde as investigaçóes do promotor independente deem combustível para os democratas tentarem dar início a um possível processo de impeachment na Câmara, a polarização política do país viria a se aprofundar ainda mais, aumentando a imprevisibilidade das eleiçóes de 2020.

Por um lado, a depender de múltiplas variáveis (por exemplo, a gravidade das acusaçôes; a capacidade dos democratas de arregimentar o eleitorado médio do país; o comportamento da mídia mainstream e a reação de Trump frente a esse cenário etc.), os democratas poderiam vir a ser capazes de apresentar seu eventual candidato dentro de uma narrativa de redenção nacional frente a uma crise sem precedentes. Por outro lado, Trump poderia se apresentar, dentro do 
mesmo contexto, como um candidato injustiçado, frente a quem um grupo de radicais estaria agindo de maneira injusta, talvez mesmo ilegal.

Como disse, esses cenários são, por ora, puramente hipotéticos, embora pareçam bastante razoáveis. O certo é que, mesmo que alguma versão deles se materialize, não está claro como se desdobrariam durante uma longa campanha presidencial, como ocorre nos Estados Unidos - cerca de um ano, período em que o foco político do país, especialmente da mídia, é quase que exclusivamente dedicado aos candidatos.

Relacionado a essas questôes, o teor das agendas e plataformas eleitorais dentro de um cenário táo polarizado não seria de forma alguma de fácil previsibilidade. Frente a um presidente defensor de uma agenda profundamente conservadora, tanto do ponto de vista econômico como cultural e social, devem os democratas apresentar uma alternativa claramente progressista (por exemplo,saúde pública universal) ou devem continuar mantendo uma versão centrista, moderada e incremental da política republicana? Conforme venham a se desenrolar os cenários, a crise de polarização econômica e sociocultural profunda que atravessa o país poderá ou não começar a ser superada.

\section{APRECIAÇÕES FINAIS: 2020 NO HORIZONTE}

Conseguirá a gigante democracia norte-americana desmontar a crise existencial em que se encontra, ou tenderá ela a se consolidar, com consequências náo de todo previsíveis, não só para o país mas também para a nossa regiáo e para o mundo como um todo?

Os recentes acontecimentos ligados à política externa dos Estados Unidos na América Latina, especialmente com relaçâo à Venezuela, assim como a escalada de tensóes com a China justificam as mais vivas preocupaçóes. Da mesma forma, em uma escala mais ampla, parece cada dia mais evidente que a democracia liberal enfrenta hoje um dos seus mais fortes questionamentos, pelo menos ao longo dos últimos setenta anos. Essa realidade se mostra cada dia mais clara na Europa, na América Latina e de maneira talvez ainda mais intensa nos Estados Unidos, seu primeiro e maior defensor ao longo dos últimos dois séculos.

A fim de se manter atraente e viável para as próximas geraçôes, éimprescindível que esse importante sistema de organização social demonstre de forma efetiva sua relevância. Para tanto, será necessário reestabelecer meios mais inclusivos de deliberação política com vistas a obter uma representaçâo mais efetiva dos diversos interesses da complexa sociedade norte-americana. Caso contrário, poderíamos estar perto de presenciar o ocaso da democracia liberal na sociedade que tem sido historicamente vista como um dos mais importantes casos históricos da aplicaçáo bem-sucedida dessa importante lógica de funcionamento político. O que parece estar em jogo, portanto, é a própria sobrevivência de uma democracia digna 
do nome no país que sempre se ocupou em projetar os valores desse sistema ao redor do mundo.

Parece certo que a continuidade de Trump no poder por mais seis anos aprofundaria a erosão institucional que vem se desenvolvendo já há algum tempo na chamada "terra dos livres". Não surpreende, pois, que, para a maioria dos analistas políticos dos Estados Unidos, a eleição presidencial de 2020 já estaria em curso. Essa será, de fato, uma das mais importantes oportunidades para os cidadãos norte-americanos tentarem reverter o longo inverno político que absorve sua nação.

Conseguirão eles contrapor os ventos do neofascismo crescente em seu país com a renovação da promessa de inclusão do chamado "sonho americano"? Ou será que já é muito tarde para a realização desse necessário objetivo? É certo que o mundo inteiro acompanhará de perto esse importante pleito, cujos resultados terâo efeitos que irão muito além das fronteiras e possíveis muros do território norte-americano.

\section{REFERÊNCIAS}

DOUGLAS, J. Supreme Court takes a giant step backward on voter rights, CNN, 11 June 2018. Disponível em: <https://www.cnn.com/2018/06/11/opinions/ supreme-court-makes-it-harder-to-vote/index.html>.

JONES, B. House Republicans who lost re-election bids were more moderate than those who won. Pew Research Center, 7 Dec. 2018. Disponível em: $<$ http://www.pewresearch.org/fact-tank/2018/12/07/house-republicans-wholost-re-election-bids-were-more-moderate-than-those-who-won/>.

KRAY, C. A.; MANDELL, H.; CARROLL, T. Republican women are just fine, thank, you, with being Republican. Quartz, 26 Oct., 2018. Disponível em: <https://qz.com/1439080/why-republican-women-vote-for-trump-andsupport-brett-kavanaugh/>.

LOPEZ, G. Voter suppression really may have made the difference for Republicans in Georgia: and that could send a message to Republicans nationwide. Vox, 7 nov. 2018. Disponível em: <https:/www.vox.com/policy-and-politics/2018/11/7/18071438/ midterm-election-results-voting-rights-georgia-florida>.

NORT, A. The midterm election shows white women are finally starting to abandon Trump: women of color have backed Democrats for years: in 2018, more white women started joint them. Vox, 7 Nov. 2018. Disponível em: <https://www. vox.com/policy-and-politics/2018/11/7/18064260/midterm-elections-turnoutwomen-trump-exit-polls>. 
NORTH CAROLINA voting laws suppress minorities, The Pitt New, 24 Oct. 2018. Disponível em: <https://pittnews.com/article/136880/opinions/north-carolinavoting-laws-suppress-minorities/>.

STEWART, E. 2018's record-setting voter turnout, in one chart. Vox, 19 Nov. 2018. Disponível em: <https://www.vox.com/policy-and-politi cs/2018/11/19/18103110/2018-midterm-elections-turnout>. 